\title{
Edward Said/Erich Auerbach: humanismo mundano e fenomenologia do exílio
}

\section{Edward Said/Erich Auerbach: bumanismo mundano y fenomenología del exilio}

\author{
Marcos Cezar Botelho de Souza* \\ Universidade do Estado da Babia, \\ Salvador, Bahia, Brasil
}

\begin{abstract}
Resumo: Para Edward Said, o exílio e a migração são operadores de leitura caros ao pensamento crítico dissonante. Na perspectiva daquilo que chamo de uma fenomenologia saidiana do exílio, o lócus enunciativo do exilado é, para o pensador palestino, um estilo ético que implica numa posicionalidade diferencial indispensável para a compreensão crítica do mundo atual. Como veremos neste artigo, mesmo que os personagens conceituais do bumanismo mundano de Said sejam, por excelência, filósofos, escritores e pensadores que experimentaram a condição de exilados, "perspectivismo do exílio" é lido, contudo, como o valor heurístico de uma posicionalidade crítica sempre fora do lugar e disponível até mesmo para aqueles que não experimentaram diretamente a migração e o desterro. Em outras palavras, este artigo procura comentar a releitura que o pensador palestino realiza, em Humanismo e crítica democrática, de Mimesis, de Erich Auerbach, propondo que o ponto de diálogo entre esses autores esteja na potência que migração e exílio desempenharam em suas trajetórias críticas.
\end{abstract}

Palavras-chave: Exílio. Edward Said. Erich Auerbach.

Abstract: For Edward Said, exile and migration are expensive reading agents to discordant critical thinking. In the perspective of what I call from a saidiane phenomenology of exile, the enunciative locus of the exile is, for the Palestinian thinker, an ethical style that implies adopting an indispensable differential position for the critical understanding of the present world. As we shall see in this essay, although the conceptual characters of Said's mundane humanism are, in principle, philosophers, writers, and thinkers who experience the condition of exiles, "perspectivism of exile" is read, however, as the heuristic value of a critical positionality Always off site is available even for those who would not directly experience migration and exile. In other words, this essay attempts to comment on Erich Auerbach's reappraisal of Mimesis in Humanism and democratic critique, proposing that the possibility of dialogue between these authors is potentiated by migration and exile in their trajectories Critical.

Keywords: Exile. Edward Said. Erich Auerbach.

* Professor do Curso de Comunicação Social - Rádio e TV da Universidade do Estado da Bahia, Doutor em Literatura e Cultura, UFBA.E-mail:marcosbotelho.br@gmail.com. 


\section{INTRODUÇÃO}

À primeira vista, a aproximação entre Edward Said e Erich Auerbach pode sugerir a formação de uma comunidade estranba - o que talvez seja. Chama atenção o fato de Said, um dos grandes nomes da Teoria Pós-Colonial e dos Estudos Culturais, propor, em seus últimos escritos, uma reavaliação do humanismo - não raro considerado, na contemporaneidade, uma metanarrativa que fundamentou filosoficamente um tipo peculiar de imperialismo cultural do Ocidente.

Em Humanismo e crítica democrática, Said esboça um "inventário" dos predecessores do seu "humanismo mundano", que, conforme o próprio autor, já se encontrava formulado, por conta dos métodos, da posição exilada e contingências históricas, em Mimesis de Auerbach (2009). Said relê Mimesis como exemplo de uma obra pertencente ao cânone ocidental, porém escrita sob o signo de um "perspectivismo do exílio" e, portanto, arejada pelo intercâmbio entre "Europa-Ocidente-Oriente-Mundo".

\section{O HUMANISMO REABERTO PARA BALANÇO}

Humanismo e crítica democrática, publicado postumamente em 2004, compõe-se de cinco capítulos amarrados por uma questão central: o lugar e o futuro do humanismo no pensamento contemporâneo, revistos à luz do exílio e da migração. Nesse livro, sugere Paul Bové,

a voz do autor exilado alcança esse amor pelo mundo prometido no abandono do seu próprio país ou da sua própria identidade. Mas preciso ser claro: a voz de Said não alcança uma espécie de visão universal do mundo tal como é; pelo contrário, opõe-se a tal possibilidade, em grande parte porque vê que o esforço de impor semelhante visão [totalizante e universalista] através do poder desumanizado ameaça a liberdade e a espécie. (2006, p.63).

Os ensaios de Humanismo e Crítica Democrática têm um caráter empenhado. Muitas vezes, adquirem uma tonalidade de dramatização política e engajamento do intelectual comprometido contra os avanços do "neoconservadorismo", tendência ideológica dominante nos debates culturais ${ }^{2}$ após os ataques terroristas do Onze de Setembro de 2001. A proposta de Said, ao longo dos capítulos, é observar "como atualmente as práticas

\footnotetext{
${ }^{1}$ Em Os Inimigos intimos da democracia, Tzvetan Todorov (2012, p.55) traça um rápido, porém certeiro, perfil dos "intelectuais neoconservadores" na França e nos Estados Unidos. Diz Todorov que "esses indivíduos percorrerão às vezes três etapas: adeptos da religião comunista antes e após 1968, com frequência numa de suas variantes de extrema esquerda, tornam-se radicalmente anticomunistas e antitotalitários alguns anos mais tarde, em consequência da difusão de informações mais amplas sobre a realidade do gulag (denominam-se então 'novos filósofos'), antes de aparecerem, nestes últimos anos, como partidários da guerra 'democrática' ou 'humanitária' no Iraque, no Afeganistão ou na Líbia”. 2 Neoconservadorismo (ou neocon, para os íntimos) é uma corrente filosófica e política norte-americana e europeia contra, entre outras agendas, o avanço político do interculturalismo, a manutenção do estado de bem-estar social, a legalização de imigrantes, entre outros. Nos Estados Unidos sua expressão política mais conhecida foi o chamado Tea Party Movement, de 2009, que defende o "originalismo" étnico e racial e o "retorno" aos valores dos "fundadores e pioneiros" dos Estados Unidos.
} 
intelectuais são, no contexto das reações mais agressivas dos Estados Norte-Americanos e da Europa Central para com o mundo, totalmente diferentes e como os deveres de um humanista às vezes entram surpreendentemente em conflito com o que agora se espera de nós - e nunca tanto depois do Onze de Setembro” (SAID, 2007, p.17).

De início, o livro resumiria os principais tópicos das conferências proferidas por Said na Universidade Columbia, em 2000. Porém, dois anos mais tarde - sob os impactos do retrocesso político pós-Onze de Setembro -, Said expandiu os limites do projeto - um balanço crítico dos legados do humanismo - para o olho do furacão do pesado ambiente ideológico, marcado por discursos e ataques xenófobos contra imigrantes e seus descendentes, especialmente contra árabes e muçulmanos, que deram o tom das contendas políticas daquele momento.

O que interveio entre as duas datas foram os acontecimentos de 11 de setembro de 2001. Uma atmosfera política modificada colheu os Estados Unidos e, em graus variados, o resto do mundo. A guerra contra o terrorismo, a campanha no Afeganistão, a invasão anglo-americana no Iraque, tudo isso deu origem a um mundo de animosidades intensificadas, a uma atitude americana muito mais agressiva para com o mundo, e - considerando a minha própria formação bicultural - a um conflito muito exacerbado entre o 'Ocidente' e o 'Islã', rótulos que há muito tempo julgo equívocos e mais apropriados para a mobilização de paixões coletivas do que para uma lúcida compreensão, enquanto não analítica e criticamente desconstruídos. (SAID, 2007, p.16).

Ao ampliar o escopo do livro, Said retomou algumas das questões já abordadas por ele em outros ensaios e polêmicas. Percebeu, então, nas camadas discursivas dos neoconservadores e analistas políticos, a sombra de antigos essencialismos e representações orientalistas, as mesmas "estruturas de referências e atitudes" - o persistente binômio entre "civilização versus barbárie" - em relação aos "novos Outros do Ocidente". A questão para Said foi, mais uma vez, entender como parte das novas alegações civilizatórias do Ocidente eram ainda documentos exemplares do orientalismo e, em todo caso, da explosão islamofóbica. Sua crítica, portanto, se dirigia com mais ênfase às forças reativas inscritas nas análises da nova face da política e da cultura contemporâneas.

A América oferece ao humanista desafios e demandas especiais diferentes daqueles apresentados por qualquer nação. Claramente, porém, como uma sociedade de imigrantes, os Estados Unidos não são um lugar homogêneo [...] cresci numa cultura não ocidental, e, como alguém que é anfíbio ou bicultural, sou especialmente consciente, creio eu, de perspectivas e tradições diferentes daquelas consideradas em geral como unicamente americanas ou 'ocidentais'. Isso talvez me propicie um ângulo de visão um pouco peculiar. (SAID, 2007, p.19).

Quanto às práticas da crítica literária, Said defende que o reexame do humanismo no presente deve passar por um retorno à filologia, cujo procedimento de leitura crítica minuciosa e comparativa dos textos talvez

seja o menos atraente, o menos excitante e menos moderno de todos os ramos da erudição 
associados com o humanismo, bem como o menos provável de aparecer em discussões sobre a relevância do humanismo para vida no início do século XXI [...] É o caso de mencionar, a fim de diminuir a resistência à noção pouco atraente de filologia como disciplina obsoleta de antiquário, que talvez o mais radical e intelectualmente mais audacioso de todos os filósofos ocidentais dos últimos 150 anos, Nietzsche, foi e sempre se considerou acima de tudo um filólogo. (SAID, 2007, p.80).

Não se trata de um trabalho específico de crítica textual ou ecdótica, nem do trato com textualidades de eras pregressas em detrimento das expressões atuais, embora Said não faça qualquer agravo a essas práticas da filologia "clássica". Trata-se especificamente de uma retomada da filologia refinada por Erich Auerbach, que amalgama análise das formas literárias e aportes conceituais da sociologia e da história, em um corpo sincrético em que as três áreas oxigenam e alargam os limites umas das outras.

O processo de leitura filológica e crítica entre a análise paciente e a resistência secular deve articular, na visão de Said, uma recepção submetida aos textos como "objetos separados", passando depois, "à força de expandir e elucidar as estruturas com frequência obscuras ou invisíveis em que eles existem, às suas situações históricas e ao modo como certas estruturas de atitude, sentimento e retórica se enredam em algumas correntes, algumas formulações históricas e sociais de seu contexto" (SAID, 2007, p.85). Esse movimento duplo, contextual e atento às formas estéticas, traduz o modo de leitura paradoxal proposto por Said: tradicional no tratamento dado à textualidade, mas intempestivo no recorte das representações históricas do mundo que informam os textos.

Ao retomar a filologia auerbachiana, Said procura recuperar também uma força mundana - perdida ou talvez apenas esquecida - dessa disciplina moderna ${ }^{3}$. "Geralmente esquecemos que a filologia ocidental moderna, que se inicia em princípios do século XIX, se comprometeu em revisar as ideias comumente aceitas acerca da linguagem e suas origens divinas" (SAID, 2004, p.68). Inicialmente como projeto secular de articulação entre a linguagem, o texto e a história, e "após fracassar em seu objetivo, passou a reduzir a linguagem a uma série de circunstâncias específicas: grupos linguísticos, teorias raciais e teses geográficas e antropológicas" (SAID, 2004, p.68), a atividade hermenêutica da filologia pode ser aplicada também na contenção dos excessos da leitura exclusivamente "sociológica" ou "ideológica" dos textos literários, embora seu compromisso mundano com as transições históricas seja um dos seus principais pontos de fuga.

Sim, precisamos sempre voltar às palavras e às estruturas nos livros que lemos, mas assim como essas palavras foram elas próprias retiradas do mundo pelo poeta, e evocadas do silêncio por meio de maneiras substanciais sem as quais nenhuma criação é possível, os leitores devem estender suas leituras para os vários mundos em que cada um de nós reside. É especialmente apropriado que o humanista contemporâneo cultive essa percepção de

\footnotetext{
3 O próprio Eric Auerbach já havia feito, ao final de Ensaios de Literatura Ocidental, um réquiem de certa tradição critico-filológica, perguntando ao leitor: "Quantos homens dominarão o conjunto do material desse campo específico, com todas as suas ramificações e direções de pesquisa? Como é possível, em tais circunstâncias, pensar numa filologia sintético-científica da literatura mundial? Ainda existem pessoas que, ao menos no tocante à Europa, dominam o conjunto do material; mas todas elas pertencem, tanto quanto sei, à geração que cresceu antes da guerra. Será difícil substituí-la, pois, nesse ínterim, a cultura humanística tardo-burguesa, que incluía o ensino do grego, do latim e da Bíblia, desmoronou por quase toda parte [...]”. (AUERBACH, 2012, p.364).
} 
mundos múltiplos e tradições complexas que interagem umas com as outras, essa inevitável combinação que mencionei de participação e distanciamento, recepção e resistência. (SAID, 2007, p.101).

O modelo de leitura saidiano transita nas fronteiras entre os discursos, a narrativa, o campo das representações e transições históricas. Esse modo de articulação já se encontra esboçado, como assinala o próprio Said, em Mimesis, de Erich Auerbach (2009), objeto do quarto capítulo de Humanismo e crítica democrática (2003) ${ }^{4}$. Causou espécie a muitos comentadores ${ }^{5}$ que Said, um intérprete polêmico da alta tradição literária europeia, cujas obras mais conhecidas, como Orientalismo e Cultura e Imperialismo, são consideradas alicerces dos estudos culturais e pós-coloniais, expressasse nesse ensaio seus débitos e afinidades com Auerbach, "filólogo moderno" que esteve exclusivamente focado na análise do cânone literário ocidental. Embora o reconhecimento da admiração de Said por Auerbach não fosse recente, alguns de seus leitores, admiradores ou não, se surpreenderam com seu "retorno" (inexistente, em minha opinião, pois Auerbach sempre foi uma referência forte para Said, inclusive em Orientalismo), já que a fama de Said, "o professor do terror", baseava-se tanto em sua práxis política, como intelectual envolvido na questão palestina, quanto na análise dos discursos da "invenção do Oriente e da alteridade" na tradição cultural ocidental. A supresa estaria no reconhecimento por parte de Said da sua "dívida" em relação a um dos maiores rebentos do pensamento europeu: Mimesis, de Erich Auerbach, obra-prima incontornável da teoria literária, lançada em 1946, cuja ênfase no cânone literário ocidental seria justamente a confirmação do eurocentrismo contra o qual se insurgiram as demandas pós-estruturalistas, culturalistas e pós-coloniais.

Então, por que Said considera Mimesis a ilustração concreta de seus argumentos acerca da viabilidade do humanismo e da crítica mundana e secular? Para ele, Mimesis é o

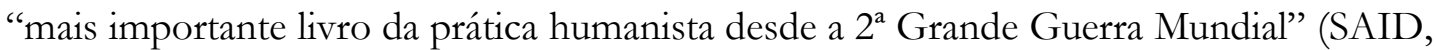
2007, p.111), cuja influência atravessaria ondas teóricas "associadas com tendências acadêmicas, a maioria das quais é rapidamente substituída por mudanças de gosto, modas ou genuína descoberta intelectual" (2007, p.111). Em 1988, Paul Bové, em seu Intellectuals in Power, já havia traçado uma genealogia do humanismo crítico, cujas dobras contemporâneas e paradoxais seriam, segundo o autor, Michel Foucault e Edward Said, mas teria no perspectivismo crítico de Auerbach uma referência básica. Conforme Bové, Mimesis seria "uma história descontínua como a história engajada do presente", e forneceria modos de pesquisa acadêmica ainda viáveis "para inquirir as atuais condições sociais e políticas das quais todo discurso cultural e intelectual emerge” (BOVÉ apud LINDENBERGER, 2004, p.01).

Said reconhece, inicialmente, a economia e a produtividade do estilo ensaístico de Auerbach, a saber: a utilização de longas citações iniciais das obras analisadas a partir das quais se desenrola uma detalhada explicação que habita a localidade do texto, num ritmo

\footnotetext{
${ }^{4}$ O capítulo quarto de Humanismo e Crítica Democrática, intitulado Introdução a Mimesis, de Erich Auerbach, é uma revisão da apresentação feita por Said para a edição comemorativa dos cinquenta anos de publicação de Mimesis em língua inglesa. Essa edição especial foi lançada em 2003, ano da morte de Said.

${ }_{5}^{5}$ Para ficar em poucos exemplos, podemos citar Homi Bhabha, Paul Bové, Bill Ashcroft, Helen Tifflin, autores com os quais dialogo neste artigo.
} 
descansado e ruminativo, desdobrando-se em comentários sobre as relações entre o estilo, as estratégias de representação da realidade e os contextos sociopolíticos. Para usar uma imagem metafórica de tal modo de análise, os fragmentos iniciais das obras avaliadas por Auerbach das quais emergem sua historicidade, geralmente imagens "cotidianas e rebaixadas" e "pouco importantes" dos textos, funcionam, em Mimesis, como pedras lançadas na superfície da água, provocando linhas de leituras concêntricas - e excêntricas - a partir das quais os sentidos latentes dos textos sobem à tona e conectam a interpretação imanente aos traços da história e da cultura. Um exemplo: no capítulo XII de Mimesis, intitulado "O Príncipe Cansado", sobre o drama Henrique V de Shakespeare, o príncipe Henrique, futuro rei Henrique V, confessa ao plebeu Poins, um dos seus companheiros de farras juvenis, estar "extremamente cansado" e desejoso por "uma cerveja fraca" ("uma cervejinha"), vontade indigna de uma pessoa de tão elevada posição, ainda mais por ser uma confissão ao subalterno Poins, que "repreende" o nobre pela concessão à prática característica da plebe. Tal detalhe burlesco, que indicia a emergência do cotidiano mundano em uma tragédia de tom elevado e sublime, é lido por Auerbach como (1) índice de uma mudança estilística (a hibridização de estilos da tragédia e da comédia); (2) uma nova abertura (múltipla e mais livre) do modo de representação do mundo quando comparada ao Século de Ouro Espanhol; e (3) um traço de relativização dos limites estamentais (um signo das transformações e tensões sociais e históricas em curso). Segundo Auerbach, na antológica coda de Mimesis, seu método de trabalho procura

apresentar, para cada época, uma certa quantidade de textos, para com base nos mesmos pôr à prova os meus pensamentos, levar imediatamente para dentro do assunto, de tal forma que o leitor chega a sentir do que se trata, antes que lhe seja impingida uma teoria. O método da interpretação de textos deixa à discrição do intérprete certo campo de ação: pode escolher e dar ênfase como preferir. Contudo, aquilo que afirma deve ser encontrado no texto. As minhas interpretações são dirigidas, sem dúvida, por uma intenção determinada; mas essa intenção só ganhou forma, paulatinamente, sempre durante o jogo com o texto, e, durante longos trechos, deixei-me levar pelo texto. Em pesquisas desta espécie, não se mexe com leis, mas com tendências e correntes que se entrecruzam e complementam da forma mais variada possível. [...] Pelo contrário, empenhei-me em acomodar os múltiplos dados e dar a minhas formulações a correspondente elasticidade. (AUERBACH, 2009, p.501).

A elasticidade proposta pelo filólogo teria relação com a articulação que ele faz entre as transformações na representação literária da "realidade", em obras literárias de períodos variados, e os modos de figuração do mundo, no devir da "invenção do humano" no Ocidente, vista por Auerbach como intrinsecamente mundana, histórica e não transcendente. Ou seja: como as variações da representação literária do "real", as imagens que os sujeitos inventaram para si mesmos, condensam e fazem emergir as mudanças históricas no mundo e vice-versa? Embora utilize o termo "realismo" em seu subtítulo, Auerbach evita a mera causalidade positivista e a atribuição de uma substância discricionária ou extemporânea ao mundano, pois entende que as obras literárias também inventam maneiras de vermos nossas relações no mundo. Como diz Leopoldo Waizbort (2013, p.178), "não se trata de atribuir, pelo investigador, um conteúdo a elas [as obras], mas algo bem diferente: descobrir como, a cada momento, os seres humanos viam, 
inventavam e compreendiam sua condição humana, representando-a literariamente", o que significa assumir a historicidade das transformações das formas de consciência e das estruturas sociais no espaço e momento em que vivem. Em suma, mais importante que as marcas de um realismo naturalista, em Mimesis, a mundanidade é tão extraordinária exatamente por isto: "é o lugar onde os homens e mulheres vivem e, portanto, é onde por assim dizer está assentada [...] sua historicidade intrínseca" (WAIZBORT, 2013, p.178).

Tal modo de leitura é reapropriado nas práticas críticas de Said: o passo inicial do ato interpretativo localiza-se no texto (suas relações com o tempo, estratégias discursivas, gêneros, efeitos de composição, traços estilísticos, modos narrativos), movendo-se, em seguida, ao tracejamento de redes periféricas exteriores (contextos político e histórico, lócus enunciativo, representação de subjetividades). Não se trata apenas de procurar estabelecer hegelianamente os reflexos do mundo na forma do texto, como na importante linha aberta pela sociologia do romance, mas de tocar o inconsciente histórico do texto.

A verdadeira leitura filológica é ativa; implica adentrar no processo da linguagem já em funcionamento nas palavras e fazer com que revele o que pode estar oculto, incompleto, mascarado ou distorcido em qualquer texto que possamos ter diante de nós. Nessa visão da linguagem, as palavras não são marcadores ou significantes passivos que representam despretensiosamente uma realidade elevada, mas antes uma parte formativa integrante da própria realidade. (SAID, 2007, p.82).

Seguramente, podemos dizer que foi em Cultura e Imperialismo (1995) que Said realizou melhor essa articulação entre o escrutínio das textualidades e formas literárias ocidentais e seus funcionamentos incompletos, com frequência obscuros ou invisíveis em que eles existem, elucidando "como certas estruturas de atitude, sentimento e retórica se enredam em algumas correntes, algumas formulações históricas e sociais de seu contexto" (SAID, 2007, p.85). Mais uma vez como Auerbach, Said cobre uma vasta área da produção cultural, analisando, agora mais "colado" às tessituras do romance europeu do século 19, passando pela ópera, poesia, meios de comunicação, chegando, porém, aos textos contrapontuais de "oposição, resistência, movimento e migração" das literaturas póscoloniais. Em um primeiro momento, o autor discute como a representação do colonialismo está incrustada na ficção europeia do século 19, principalmente em obras canônicas, como os romances - só aparentemente "ingênuos" - de Jane Austen, entre outros. Utilizando e suplementando a lição de leitura de Auerbach, Said traz o pano de fundo - os cenários e as implicações da empresa colonial latentes nos quadros europeus criados pelo romance realista - para a superfície da análise, assinalando como essas narrativas dão pistas sobre a consolidação das "atitudes e referências" que balizavam as relações entre o centro imperial e as colônias. Assim, a partir de uma rápida e pouco importante "passagem mundana" do romance Mansfield Park, de Austen (2011), aquele parágrafo em que a autora narra a volta de sir Thomas Bertram, após longo período nas fazendas de Antígua, "seu jardim colonial" no Caribe, Said desencadeia então uma análise ruminativa ${ }^{6}$, ao estilo de Auerbach. Vejamos a cena de Austen:

${ }^{6}$ Aqui resumida apenas como exemplo casuístico. 
Foi uma manhã azafamada para ele. As conversas com cada um deles ocuparam apenas uma pequena parte. Ele tinha que se instalar em todas as ocupações habituais de sua vida em Mansfield, ver o administrador e o intendente - examinar e fazer as contas - e, nos intervalos dos negócios, percorrer os estábulos e os jardins, e as plantações mais próximas; mas, ativo e metódico, não só tinha feito tudo isso antes de retomar seu lugar como dono da casa à hora do almoço, como também mandara o carpinteiro desfazer tudo o que havia sido montado na sala de bilhar [...] E sir Thomas tinha a esperança de que mais um ou dois dias bastariam para acabar com qualquer resquício exterior do que acontecera, até a destruição de todos os exemplares avulsos de Juras de amor na casa, pois ele estava queimando tudo o que lhe aparecia pela frente. (AUSTEN apud SAID, 1995, p.128).

Partindo desse parágrafo do romance, a análise de Said ruma em círculos concêntricos, expondo as afinidades entre as passagens da expressão textual e o "todo do mundo", ou seja, suas ressonâncias históricas e sociais.

A força deste parágrafo é inequívoca. Não é apenas um Crusoé pondo as coisas em ordem: é também um antigo protestante eliminando os traços de comportamento frívolo. Nada em Mansfield Park nos desmentiria, porém, se fôssemos supor que sir Thomas faz exatamente as mesmas coisas - em escala mais ampla - em suas 'fazendas' de Antígua. Tudo o que estivesse errado por lá, [...] a depressão econômica, a escravidão e a concorrência com a França, sir Thomas foi capaz de endireitar, assim mantendo o controle sobre seu domínio colonial. Aqui, mais do que em qualquer outra parte da obra, Auster estabelece uma sincronia entre a autoridade doméstica e a autoridade internacional. [...] O que assegura a tranquilidade doméstica e a atraente harmonia de uma é a produtividade e a disciplina regrada da outra. (SAID, 1995, p.128).

Para Said, não se trata, é claro, de transformar Jane Auster numa agente colonial do imperialismo britânico. Longe disso. Ele principia com um texto produzido por uma autora cujo valor literário e o desinteresse pelas questões políticas são notáveis justamente para comentar a "naturalização" da representação colonialista no inconsciente político do romance europeu do século 19, o qual "coincidiu" com o auge da expansão imperialista e, de certa forma, a representou numa relação mundanamente complexa. Assim, mesmo sendo um truísmo - toda interpretação é passível de releituras posteriores -, a força de uma grande obra está na sua capacidade de produzir mais e mais complexidade,

tornando-se com o tempo o que Raymond Williams chamou de uma teia inteira de notações culturais com frequência contraditórias. Até os romances talentosamente construídos de Jane Austen, por exemplo, são associados com as circunstâncias de seu tempo; é por essa razão que ela faz referências elaboradas a práticas sórdidas como a escravidão e às lutas pela propriedade. No entanto, repetindo, os seus romances jamais podem ser reduzidos apenas às forças sociais, políticas, históricas e econômicas, mas antes estão, antiteticamente, numa relação dialética não resolvida com essas forças, numa posição que obviamente depende da história, mas que não é redutível a ela. (SAID, 2009, p.87).

Auerbach continou no pensamento de Said como um som de baixo fundo após Orientalismo e uma referência forte para sua crítica a partir do lugar heurístico do exílio. Como fica claro em Crítica Secular, ensaio introdutório de O Mundo, o texto e a crítica, escrito 
em 1983, a inspiração de Auerbach estabeleceu, para Said, uma postura analítica presente em toda sua carreira de crítico diaspórico. Aqui Said já comentava como Auerbach havia alcançado um distanciamento e um ponto de partida diferenciado, cavando uma "toca" dentro da própria tradição que estudava e, apesar de sua perspectiva supostamente eurocêntrica, produziu um modelo de crítica oposicional. É, portanto, essa posição exilada de Auerbach, "um desorbitado náufrago do sentido, da nação e do entorno" (SAID, 2004, p.17), que constitui, para o crítico palestino, outra perspectiva potencial. Para Said, o exílio de Auerbach o obrigou a olhar a própria tradição europeia de um lócus enunciativo "fora do lugar, exilado, alienado" (SAID, 2004, p.20). Ele completa:

[...] sem dúvida, Auerbach assinala de forma explícita que foi precisamente sua distância do lugar - em todos os sentidos da palavra - que o permitiu assumir esse soberbo desafio de Mimesis. Como deixou de ser o exílio um desafio ou um risco, ou inlusive uma ameaça que pairava sobre sua individualidade européia, para converter-se em uma missão positiva cujo êxito chegaria a ser um ato cultural de enorme importância? A resposta a esta pergunta deve ser buscada em um ensaio da época madura de Auerbach intitulado 'Philologie der weltliteratur'. A parte mais importante do ensaio deselvolve a ideia, anunciada de forma explícita pela primeira vez em Mimesis, porém já reconhecida no interesse de Auerbach por Vico, de que o trabalho filológico se ocupa com a humanidade em geral e transcende as fronteiras nacionais. Como ele disse, 'nosso lugar filológico é a terra e já não pode ser a nação'. Seu ensaio deixa claro, não obstante, que seu lugar terreal é a cultura européia. Porém, ato contínuo, como se estivesse lembrando o período de seu exílio extraeuropeu no Oriente, acrescenta: 'Ainda assim, uma parte valiosa e indispensável da herança de um filólogo seja a cultura e a herança da própria nação [...] Sem dúvida [o trabalho do crítico] só se torna efetivo quando fica apartado pela primeira vez deste lugar e depois o transcende'. (SAID, 2004, p.18. Grifos do autor).

Said costuma tomar como uma espécie de refrão da "crítica secular e mundana" uma citação feita por Auerbach, no final de Filologia da Literatura Mundial (AUERBACH, 2012, p.357), de uma passagem escrita por Hugo de Saint Victor, em Disdacalion, "como um modelo para quem queira transcender os limites nacionais e provinciais" (SAID, 2003, p.59). Após afirmar que a "pátria do crítico é a Terra" e que - embora a língua e a cultura por ele herdadas continuem indispensáveis - é "preciso afastar-se delas e superá-las para que se tornem eficazes, [...] pois o espírito não é nacional”, Auerbach cita essas linhas precisas de Saint Victor, que são de fato surpreendentes quando sabemos que o autor era um religioso saxão do século XII:

portanto, é fonte de grande virtude para a mente exercitada aprender, pouco a pouco, primeiro a mudar em relação às coisas invisíveis e transitórias, de tal modo que depois ela possa deixá-las para trás completamente. O homem que acha doce seu torrão natal ainda é um iniciante fraco; aquele para quem todo solo é sua terra natal já é forte; mas perfeito é aquele para quem o mundo inteiro é uma terra estrangeira. (HUGO SAINT VICTOR apud SAID, 2003, p.58).

O cosmopolitismo e o antiparoquialismo de Auerbach são, portanto, alguns dos aspectos fundamentais na leitura de Said. Mimesis é tanto um ensaio de longo escopo sobre a dinâmica das representações da realidade na literatura ocidental, quanto "o livro pessoal 
de um exilado" (SAID, 2007, p.122). Escrito em alemão por um judeu exilado em Istambul, cuja educação prussiana clássica hibridizava-se com a formação do filólogo erudito em cultura latina, Mimesis, mesmo sendo uma afirmação da literatura europeia, "é também um livro de contracorrentes, ironias e até contradições que precisam ser levadas em consideração para que ele seja lido e compreendido de maneira apropriada" (SAID, 2007, p.122). O ponto de leitura de Said é que a relação de Auerbach com a tradição da cultura ocidental (não apenas por conta da sua experiência expatriada) já é um exílio, uma condição problemática dramatizada pelo deslocamento literal para Istambul - um lugar importante da "não-Europa" - mas também devido ao trabalho de um vida sobre textos da cultura latina. Segundo Aamir Mufti (1998), "Said lê Auerbach em um sentido rigoroso como uma figura judaica, como membro de uma minoria, de uma minoria por excelência". Em um texto posterior a Mimesis, Auerbach assume, bem ao seu estilo discreto, os influxos de sua condição exilada como traço indelével do livro: "Mimesis é, de modo absolutamente consciente, um livro escrito por um determinado homem, em uma determinada situação, no começo dos anos de 1940" (AUERBACH apud WAIZBORT, 2004, p.81). Outra singularidade auerbachiana valorizada por Said, índice do cosmopolitismo exilado do autor, é seu esforço em superar (o que não era pouca coisa à época) a tradição do volkesgeits nacionalista (naquele momento já periculosamente institucionalizado por regimes políticos totalitários) da influente linha teórica germânica inaugurada por Herder (e seguida pelo Romantismo, por Hegel, entre outros), que vinculava a história literária e a filologia às fronteiras das identidades nacionais. $O$ exílio de Auerbach foi motivado por questões de perseguição étnico-religiosas, como se sabe, mas em Mimesis se configura também, nas entrelinhas, uma visão ética da literatura como um lócus de transnaciolismo potencial, em um contexto de extremado nacionalismo e violência institucionalizada.

\section{FILOLOGIA NO EXÍLIO}

Auerbach é, para Said, uma "representação do intelectual diaspórico", eleição que entrou na conta de seus muitos paradoxos, segundo a leitura de seus críticos. Por que os exilados que elege são intelectuais europeus canônicos que, de certa forma, não estão (ou foram) completamente "obrigados" ao exílio forçado, a exemplo de outros refugiados políticos? A resposta de Said está numa outra perspectiva da violência do expatriamento: a avaliação do pensamento desses intelectuais modernos do cânone ocidental, como Theodor Adorno e Erich Auerbach, dá-se no sentido de entender como estes autores se posicionaram e formularam, a partir da condição intervalar do exílio, uma crítica de dentro - e de fora - das culturas às quais pertenciam. Daí que Said releia Mimesis como uma obra marcada constitutivamente pela dupla perspectiva do exilado: Auerbach consegue ver, na visão de Said, cada cena ou situação histórica numa dialética entre o lugar de asilo e seu espaço de origem. Said não encontra, em Mimesis, apenas acumulação erudita ou anos de esforços pacientes a serviço da compreensão de textos antigos e contemporâneos. Descobre também um intelectual atento aos sentidos da modernidade e da "queda da Europa" - da Alemanha particularmente - a partir do seu desterro turco. É como se, em Mimesis, Auerbach visse, mesmo que indiretamente, o esgotamento da própria civilização 
ocidental, na rarefação do realismo-naturalista que percebe no tratamento dado à representação da realidade na obra de Virgínia Woolf, por exemplo, como um sintoma dilacerante da literatura em meio à barbárie dos regimes totalitários, um dilema propriamente literário e um filtro de leitura da tradição.

Em Mimesis assoma a consciência, como afirma Castro Rocha (2013, p.11), de "um livro escrito por um judeu alemão, exilado em Istambul". Daí que Said, um árabepalestino-americano, paradoxalmente se identifique com a condição de Auerbach, um intelectual judeu também especialista em cultura cristã europeia, alemão e estudioso das literaturas latinas, que escreveu sua obra no exílio. Ser exilado na Turquia, à época, não era pouca coisa. Istambul representava, como diz Said, "o terrível Turco, assim como o Islã, o flagelo da cristandade, a encarnação da grande apostasia oriental” (SAID, 2004, p.18), armadilhas orientalistas das quais Auerbach conseguiu escapar. Vale lembrar que Auerbach, em Introdução aos estudos literários (2015), escrito em 1943 - destinado a objetivos didáticos com seus alunos turcos - e que preparou Mimesis, relativiza a expressão "invasões bárbaras", como era usual na historiografia ocidental quando se tratava das ondas de deslocamentos de povos desencadeadas na Europa com as incursões dos hunos do século 4, preferindo chamá-las de "migração dos povos" (Völkerwanderung), reconhecendo, mais adequadamente, o papel fundante destas na formação histórica das culturas europeias.

De fato, os paradoxos produtivos do exílio tornam-se evidentes em muitos momentos de Mimesis. Auerbach desembarcou em Istambul tangido pela perseguição do nacional-socialismo nazista para substituir Leo Spitzer, outro grande filólogo humanista e romanista, que o antecedeu no exílio e na docência na Turquia. Como afirma Castro Rocha (2013, p.11), Auerbach participou, por conta das contingências históricas do exílio, da missão modernizadora posta em curso por Kenal Aratürk, articulador do Estado Moderno laico e democrático na Turquia, o qual

\footnotetext{
deveria favorecer a reconstrução de uma idealizada essência turca, que, assim, seria reencontrada mais adequadamente através do olhar europeu. A ironia é cortante, porém a experiência turca é perigosamente familiar [a Auerbach]. Na sua eloquente descrição, o exercício crítico repousa num 'duplo quase': o filólogo deveria quase tornar-se nativo de diversas literaturas, e, ao mesmo tempo, deveria quase tornar-se estrangeiro a seu próprio horizonte cultural.
}

No epílogo de Mimesis, Auerbach agrega à visão do exílio de Hugo de Saint Victor, os conceitos de paupertas (carência) e de terra aliena (terra estrangeira), às condições "menores" do exílio, o "duplo quase", como fatores importantes do seu projeto, sustentando que o indicador estético da insuficiência voluntária do lugar é também uma abertura para aquele que deseja desenvolver considerável apreço pela mundanidade (SAID, 2004, p.19). Por isso, mesmo que lamente as carências materiais do exílio, Auerbach admite, por entre o tom de modéstia, que as contingências de sua categoria exilada e a falta do lugar repercutiram e criaram as descontinuidades do seu perspectivismo analítico. Talvez, como sublinha Said, se Auerbach tivesse buscado realizar um trabalho academicamente "meticuloso no estilo tradicional, jamais tivesse escrito o livro: a própria 
cultura, com seus agentes autorizados e sancionadores, teria impedido tão audaz labor a um só homem. Daí o valor executivo do exílio que Auerbach conseguiu converter em utilidade efetiva" (SAID, 2004, p.20). Ou seja, foram justamente o seu distanciamento do lugar de origem, o Ocidente, e sua localização no exílio oriental os aspectos que conferiram a Mimesis seu maior desafio, mas também uma incompletude, tornando-o um livro marcado por deslocamentos e renúncias a totalizações, arejado pela elasticidade crítica e "por um drama extraordinariamente absorvente no autor e no livro" (SAID, 2007, p.110). Diz Auerbach, ao final de Mimesis, que em seu exílio na Turquia

as dificuldades eram demasiado grandes; [...] e muito frequentemente tive que abandonar o âmbito que me é próprio, as literaturas românicas. Junta-se a isto, ainda, o fato de a pesquisa ter sido escrita durante a guerra, em Istambul. Aqui não há nenhuma biblioteca bem provida para estudos europeus; as comunicações estavam paralisadas; de tal forma que tive de renunciar a quase todas as publicações periódicas, à maioria das pesquisas recentes. [...] Aliás, é bem provável que este livro deva agradecer a sua existência precisamente à falta de uma grande biblioteca especializada; se tivesse podido tentar informar-me a respeito de tudo o que foi feito acerca de tantos temas, talvez nunca tivesse chegado a escrevê-lo. (AUERBACH, 2009, p.502).

Mas Auerbach não lamenta apenas a falta de "bibliografia ocidental" atualizada em Istambul, atitude que sugeriria a superioridade do intelectual europeu observando a precariedade material do outro, mas escreve, em Mimesis (2009, p.463), que "na Alemanha, a própria vida era mais provinciana, mais antiquada, muito menos 'contemporânea" se comparada à França. Auerbach critica também a paradoxal exclusão das tradições islâmicas do projeto de "modernização periférica" empreendido pelos próprios mandatários do Estado-Nação turco. Em carta enviada do exílio a Walter Benjamin ${ }^{7}$, em 1937, ele comenta as ambivalências do contexto político e institucional da reforma da Universidade de Istambul e lamenta a recusa, por parte dos reformadores universitários, "de toda a tradição cultural muçulmana existente, ligação com uma quimérica turquidade (Urtürkentum), modernização técnica no sentido europeu, para bater a odiada e admirada Europa com suas próprias armas" (AUERBACH apud ROCHA, 2013, p.11). Portanto, no balanco dos contratempos identitários do exilado, Auerbach não particulariza somente a Turquia dos anos 1930, mas antes "representava uma marca da modernidade. Pelo contrário, com olhar de antropólogo, Auerbach descobriu no dilema turco a radicalização de um fenômeno mais amplo, a ponta visível do iceberg encalhado na outra margem do Atlântico". (ROCHA, 2013, p.11).

\footnotetext{
${ }^{7}$ Em outra carta enviada a Benjamin, a perspectiva do exilado na Turquia faz Auerbach virar o espelho eurocêntrico de ponta-cabeça, "tornando a experiência turca espelho inesperado da crise da consciência europeia": "Caro Senhor Benjamin, [...] Este retrato, que noutros países, como a Alemanha e a Itália e também a Rússia (?) ainda não é visível para todos, aqui se mostra em absoluta desnudez. [...] Poderia encher várias páginas com detalhes; o todo pode ser resumido nesta direção: torna-se, para mim, cada vez mais claro que a situação do mundo contemporâneo não mostra senão o ardil da Providência que, por um caminho sangrento e doloroso, nos conduz à internacional da trivialidade e a uma cultura-esperanto. Já o pressentia na Alemanha e na Itália, face à horrenda falsidade da propaganda fundada no sangue e no corpo (Blubopropaganda). Mas só aqui adquiri quase certeza”. (AUERBACH apud ROCHA, 2013, p.11)
} 


\section{FENOMENOLOGIA DO EXÍLIO}

Por Auerbach conferir ao exílio um estatuto fundante em sua produção crítica, transformando os riscos da expatriação em um valor afirmativo e dissonante, Edward Said incorpora Mimesis como uma das obras precursoras de sua fenomenologia do exílio, inspirada também, arrisco dizer, no Minima Moralia, de Theodor Adorno (2001), obra escrita entre 1944 e 1947, durante o exílio do filósofo alemão que, após a ascensão do nacional-socialismo em janeiro de 1933, se viu obrigado a emigrar, primeiramente para a Inglaterra, e depois, em 1938, para os Estados Unidos, onde o Instituto de Pesquisas Sociais, dirigido por Max Horkheimer, já estava em funcionamento.

Minima Moralia é uma colagem de anotações dispersas e aforismos acerca da sociedade, da estética e da cultura massiva, cujo subtítulo, Reflexões a partir da vida danificada, traduz os efeitos da fragmentação do exílio na vida do intelectual humanista emigrado. Adorno afirma ter escrito o livro,

em grande parte, ainda durante a guerra, em condições de contemplação. A violência, que me banira, impedia-me ao mesmo tempo o seu pleno conhecimento. [...] Parte-se do mais restrito âmbito privado, do intelectual na emigração. Nele se inscrevem considerações da mais ampla esfera social e antropológica; elas concernem à psicologia, à estética, à ciência na sua relação com o sujeito. (ADORNO, 2001, p.7).

Dessa autobiografia feita de estilhaços e flagrantes do desterro político, Said extrai mais um exemplo para sua interpretação fenomenológica do exílio como um ethos do pensamento crítico dissonante, que se opõe àquilo que Adorno chama de "mundo administrado".

Todo o intelectual no exílio é, sem excepção, prejudicado e faz bem em reconhecê-lo, se não quiser que lho façam saber de forma cruel por detrás das portas hermeticamente fechadas da sua auto-estima. Vive num ambiente que lhe deve permanecer incompreensível, por mais que saiba das organizações sindicais ou do tráfego urbano; estará sempre desorientado. Entre a reprodução da sua própria vida sob o monopólio da cultura de massas e o trabalho responsável há um hiato irreconciliável. (ADORNO, 2001, p.22).

Segundo o filósofo alemão, as experiências traumáticas da Segunda Grande Guerra Mundial, a maioria em nome de pertencimentos nacionalistas autoritários, como o fascismo, o nazismo e o stalinismo, desencadearam ondas de dispersão real e existencial, tornando um traço da vida moderna "não se sentir em casa na própria casa" (ADORNO, 2001, p.28). Esse choque traumático, para Adorno, abalou as relações entre os sujeitos e seus lugares de origem, transformando a morada fixa tanto em mercadoria descartável e lares pré-fabricados quanto em lugar "perigoso" e irrecuperavelmente pretérito. Naquele momento específico, Adorno afirmava que "a casa é passado":

O modo como hoje está a situação na vida privada mostra-se no seu cenário. Em rigor, já não é possível o que se chama habitar. As habitações tradicionais em que crescemos tornaram-se insuportáveis: cada sinal de conforto se paga nelas com a traição ao conhecimento, cada forma de recolhimento com a bafienta comunidade de interesses da 
família. As novas, que fizeram tabula rasa, são estojos fabricados por peritos para filisteus, ou alojamentos operários transviados na esfera do consumo, sem qualquer relação com quem os habita; fustigam na face o anelo, já inexistente, de uma existência independente. (ADORNO, 2001, p.28).

O bombardeio das cidades europeias, bem como os campos de trabalho e de concentração, teriam sido apenas antecedentes do que o desenvolvimento imanente da tecnocracia decidiu o que seria o destino das casas, que servem só para serem lançadas fora, "como velhas latas de conserva. Como em toda a parte, o pior cabe àqueles que não têm escolha. Habitam, se não em bairros de lata, então em bungalons que amanhã poderão ser já as suas barracas, caravanas, automóveis, acampamentos, morada ao ar livre. A casa foi-se" (ADORNO, 2001, p.28).

No entanto, os termos "lar, casa e morada" têm valor ambivalente em Said: além da sua acepção material, têm também sentido heurístico e conceitual, podendo ser lidos como sinédoques que, essencialmente, se referem aos "domínios" (de domus, domicílios) estáveis do pensamento crítico, já que "a linguagem é jargão, os objetos são para venda e recusar esse estado de coisas é a missão do intelectual exilado" (SAID, 2003, p.58). Daí que "casa, lar e morada" possam ser - o que acontece com mais frequência em Said do que em Adorno - espacializados em outras formas mais abrangentes, e não menos abstratas, como pátria, nação, território, identidades defensivas etc. Contudo, para Adorno, o único lugar, a última morada possível, na qual o sujeito pode habitar ainda com alguma probabilidade de resistência e desordem em relação ao mundo desterrado, é a escrita, um espaço de exílio interior. Como diz Adorno no aforismo 51 de Minima Moralia: "o escritor organiza-se no seu texto como em sua casa. Comporta-se nos seus pensamentos como faz com os seus papéis, livros, lápis, tapetes, que leva de um quarto para o outro, produzindo uma certa desordem. [...] Quem já não tem nenhuma pátria, encontra no escrever a sua habitação" (2001, p.76).

Por outro lado, é impossível separar essa aproximação adorniana em Said sem lembrar a importância capital que a questão da Palestina exerce em seu pensamento. As metáforas topológicas, retiradas de Minima Moralia, reverberam evidentemente os territórios ocupados da Palestina e o desalojamento dos palestinos. O subtexto saidiano sobre, e às vezes contra essas construções simbólicas, teria a ver também com os conflitos israelenses-palestinos, cujo ponto nodal gira, notadamente, em torno do povoamento sionista e do despovoamento palestino, assim como dos direitos "à casa e à morada nos territórios ocupados" em Israel e na Palestina. Também não foi por acaso que o start do exílio como conceito teórico em Said tenha sido sincrônico a sua entrada nos debates sobre "a questão Palestina"". Como afirma o próprio Said, foi a sua experiência exilada de intelectual palestino-americano que predispôs a sua atenção crítica em favor das condições subjetivas que se referem essencialmente à expatriação ou aos "povos indocumentados", mas que parecem destinar-se a permanecerem a alguma distância do sólido descanso das territorializações culturais. Assim, seguir Adorno

${ }^{8}$ Os ensaios escritos por Said entre 1977 e 1979 sobre os impasses políticos, a ocupação sionista de Israel nos territórios da Palestina, assim como sobre os temas do exílio entre os palestinos, estão coligidos em A Questão da Palestina, lançado no Brasil pela editora Unesp, em 2012. 
é ficar longe de 'casa', a fim de olhá-la com o distanciamento do exílio, pois há mérito considerável em observar as discrepâncias entre os vários conceitos e o que eles produzem de fato. Damos como certas a pátria e a língua, elas se tornam natureza, e seus pressupostos subjacentes retrocedem para o dogma e a ortodoxia. $\mathrm{O}$ exilado sabe que, num mundo secular e contingente, as pátrias são sempre provisórias. Fronteiras e barreiras, que nos fecham na segurança de um território familiar, também podem se tornar prisões e são, com frequência, defendidas para além da razão ou da necessidade. O exilado atravessa fronteiras, rompe barreiras do pensamento e da experiência. (SAID, 2003, p.58).

A visão do exílio em Adorno tem também outras ressonâncias suplementares e ambivalentes em Said. Segundo Said, Adorno, "paradoxal, irônico, impiedoso, foi o intelectual por excelência, odiando todos os sistemas, do nosso lado ou do deles, com igual aversão" (SAID, 2005, p.63, Grifo nosso), cuja expatriação exacerbou sua combinação de afastamento das origens com o distanciamento crítico em relação ao cotidiano. Eis outro paradoxo: Said não leva em conta as diferenças de condições entre o "velho" exilado europeu - o qual, mesmo com todas as agruras do exílio, foi de alguma maneira "acomodado" materialmente num sistema institucional no lugar de chegada - e as dificuldades reais vividas pelos novos desterrados no mundo de adoção, cuja recepção é sempre mais problemática. Contudo, tal ambivalência pode ser lida paradoxalmente como um princípio coerente com a ética de Said. Ele sabe que não pode "falar" pelos novos imigrantes e refugiados "reais", produtos das recentes fraturas de "sociedades que suportaram o despotismo da colonização e do imperialismo", mas pode fazer ecoar, a partir de sua posição e de outros intelectuais exilados, "a perifericidade e a marginalização como um reflexo de sua determinação mais do que da hospitalidade do Ocidente" (ASHCROFT, AHLUWALIA, 2000, p.47). É plausível considerar que o interesse de Said seja não especificamente pela intensidade "negativa" com que Adorno viveu o exílio, mas a forma intempestiva em que escreveu contra o regime totalitário que o levou ao exílio, assim como contra o próprio sistema que o acolheu.

Apesar disso, Said ressignifica a "negatividade sombria" de Adorno quanto à emigração. O que interessa a Said em Minima Moralia é o aproveitamento que Adorno faz do desterro como um imperativo da tarefa crítica do intelectual diaspórico. O pensamento crítico, segundo Said, deve permanecer cético e alerta, recusando a comodidade da especialização, os afagos do poder e - fundamentalmente - o silêncio da neutralidade política, todas essas formas de "moradas" e localizações restritivas.

Conquanto reconheça em Adorno um exemplo da representação do intelectual como "um exilado permanente, que se desvia tanto do velho como do novo com a mesma destreza" (SAID, 2003, p.66), mantendo inclusive o próprio estado intermediário do exílio sob suspensão - já que esta posição pode também se tornar um lugar de moradia cômoda -Said suplementa a ausência, na obra de Adorno, dos "prazeres do exílio, as soluções de vida diferentes e os ângulos de visão excêntricos que ele pode às vezes permitir ao intelectual, estimulando sua vocação, sem talvez aliviar toda e qualquer angústia ou sentimento de amarga solidão" (SAID, 2005, p.66). Ora, se o desenraizamento provoca a marginalização e a perda parcial de referências fixas do lugar de origem, pode ser também 
uma condição vital para o intelectual que, mesmo não sendo realmente um imigrante, se localize na condição de exilado e não a alie "à lógica do convencional, e sim ao risco da ousadia, à representação da mudança, ao movimento sem interrupção" (SAID, 2005, p.70). Estar em sintonia com mais de uma cultura pode dar ao exilado uma consciência em "contraponto" das dimensões simultâneas da realidade, pois a vida do exilado, descentrada e vivida na periferia da ordem estabelecida, pode criar suas próprias estruturas de significado.

\section{REFERÊNCIAS}

ASHCROFT, Bill; AHLUWALIA, Pal. Edward Said: la paradoja de la identidade. Trad. Victor Pozanco. Barcelona: Edicions Bellaterra, 2000.

ASHCROFT, Bill, GRIFFTHS Gareth, TIFFIN, Helen. The empire writes back: Theory and practice post-colonial literatures. London: Routledge, 1991.

ASHCROFT, Bill, GRIFFTHS Gareth, TIFFIN, Helen (Orgs.). The post-colonial studies reader. London: Routledge, 1995.

AUERBACH, Erich. Mimesis: a representação da realidade na literatura ocidental. $5^{\circ}$ edição. São Paulo: Perspectiva, 2009.

AUERBACH, Erich. Ensaios de literatura ocidental. Trad. Samul Titan Jr. e José Marcos Mariani. São Paulo: Duas Cidades; Editora 34, 2012.

AUERBACH, Erich. A Novela no início do Renascimento - Itália e França. Trad. Tercio Redondo. São Paulo: Cosac Naify, 2013.

AUERBACH, Erich. Introdução aos estudos literários. Trad. José Paul Paes. São Paulo: Cosac Naify, 2015.

AUSTEN, Jane. Mansfilde Park. Trad. Mariana de Menezes Neumann. Rio de Janeiro: Bestbolso, 2011.

BHABHA, Homi K. O Local da cultura. Trad. Myrian Ávila, Eliana Lourenço Reis e Gláucia Renate Gonçalves. Belo Horizonte: Ed. UFMG, 1998.

BHABHA, Homi K. O Bazar global e o clube dos cavaleiros ingleses Trad. Teresa Dias Carneiro. Rio de Janeiro: Rocco, 2011.

BILGRAMI, Akeel. Apresentação a Humanismo e crítica democrática. In: SAID, Edward W. Humanismo e crítica democrática. Trad. Rosaura Eichenberg. São Paulo: Companhia das Letras, 2007. 
BOVÉ, Paul A. Continuando la conversación. In: BHABHA, Homi K. Edward Said, continuando la conversación. Trad. Laura Wittner. Buenos Aires: Paidós, 2006.

BOVÉ, Paul A. Intellectuals in power: a genealogy of critical humanism. New York: Columbia University Press, 1988.

CANCLINI, Néstor García. Argentinos en México: una visión antropológica. In: YANKELEVICH, Pablo. En México, entre exílios: una experiência de sudamericanos. Cidade do Mé-xico: Plaza y Valdés Editorial, 1998.

CUSSET, François. A Filosofia francesa: influência de Foucault, Derrida, Deleuze \& Cia. Trad. Fátima Murad. Porto Alegre: Artmed, 2008.

HANSEN, João Adolfo. Mimesis: Figura, Retórica \& Imagem. In: Erich Auerbach: $5^{\circ}$ Coló-quio UERJ. Rio de Janeiro: Imago Ed., 1994.

MUFTI, Aamir R. Auerbach in Istanbul: Edward Said, Secular Criticism and the question of minority culture. Critical Inquiry Vol. 25, No.1 (Autumn, 1998), pp.95-125, The University of Chicago Press, 1998.

NIETZSCHE, Friedrich. Humano, demasiado bumano: um livro para espíritos livres. Trad. Paulo César de Souza. São Paulo: Companhia das Letras, 2005.

ROCHA, João Cezar de Castro. Mimesis: Erich Auerbach em exílio (1). Rascunho Jornal de Literatura do Brasil, Curitiba, outubro de 2013, edição 162, p.11.

ROCHA, João Cezar de Castro. Erich Auerbach em exílio (2). Rascunho - Jornal de Literatura do Brasil, Curitiba, novembro de 2013, edição 163, p.11.

SADER, Emir. Said: de civilizações e barbáries. In: CLEMESA, Arlene (Org.). Edward Said: trabalho intelectual e crítica social. São Paulo: Editora Casa Amarela, 2005.

SAID, Edward W. Orientalismo: o Oriente como invenção do Ocidente. Trad. Tomás Rosa Bueno. São Paulo: Companhia das Letras, 1990.

SAID, Edward W. Orientalismo revisto. In: HOLLANDA, Heloísa Buarque (Org.). Pósmodernismo e política. Rio de Janeiro: Rocco, 1991.

SAID, Edward W. Cultura e imperialismo. Trad. Denise Bottman. São Paulo: Companhia das Letras, 1995.

SAID, Edward W. Reflexões sobre o exilio e outros ensaios. Trad. Pedro Maia Soares. São Paulo: 
Companhia das Letras, 2003.

SAID, Edward W. El Mundo, el texto y el critico. Trad. Ricardo Garcia Pérez. Buenos Aires: Debate, 2004.

SAID, Edward W. Freud e os não-europeus. Trad. Arlene Clemesha. São Paulo: Boitempo, 2004.

SAID, Edward W. Representações do intelectual: as conferências de Reith de 1993. Trad. Milton Hatoum. São Paulo: Companhia das Letras, 2005.

SAID, Edward W. Humanismo e crítica democrática. Trad. Rosaura Eichenberg. São Paulo: Companhia das Letras, 2007.

SAID, Edward W. Fora do lugar: memórias. Trad. José Geraldo Couto. São Paulo: Companhia das Letras, 2007.

TODOROV, Tzvetan. O homem desenraizado. Trad. Christina Cabo. Rio de Janeiro, São Paulo, 1999.

TODOROV, Tzvetan. Os inimigos intimos da democracia. Trad. Joana Angélica d'Ávila Melo. Rio de Janeiro, São Paulo, 2012.

WAIZBORT, Leopoldo. Erich Auerbach e a condição humana. In: ALMEIDA, Jorge, BADER, Wolfgang. O Pensamento alemão no século XX - Volume 2. São Paulo: Cosac Naify, 2003.

WALIA, Shelley. Edward Said y la historiografia. Barcelona: Gedisa, 2001.

Recebido em: 28/03/2017

Aprovado em: 25/05/2017

Publicado em: 01/06/2017 